\title{
Protective Measures for Humans against Avian Influenza A(H5N8) Outbreaks in 22 European Union/European Economic Area Countries and Israel, 2016-17
}

\author{
Cornelia Adlhoch, Gavin Dabrera, Pasi Penttinen, Richard Pebody, on behalf of Country Experts ${ }^{1}$
}

We sought to better understand national approaches for managing potential human health risks during outbreaks of infection with avian influenza A(H5N8) virus during 201617. Twenty-three countries in the Union/European Economic Area and Israel participated in this study. Risk to the general public was assessed as low in 18 countries and medium in 1 country. Of 524 exposed persons identified, 274 were passively monitored and 250 were actively monitored. Of 29 persons tested, all were negative for H5N8 virus. Vaccination and antiviral drug recommendations varied across countries. A high level of personal protection was recommended although a low risk was assessed. No transmission of this virus to humans was identified.

$\mathrm{O}$ utbreaks of highly pathogenic avian influenza A(H5N8) pose a challenge for the food production industry and veterinary and public health services. This disease might cause losses of large numbers of animals, spread rapidly within and between countries, and entail transmission to humans. Several avian influenza outbreaks in avian species have been associated with severe illness in persons directly exposed to birds in these events (1-6). All novel influenza strains detected in humans are reportable under European Union (EU) legislation and the International Health Regulations (2005) (7-9).

Evolution, adaptation, and frequent reassortment create new avian influenza viruses that might be transmitted to humans, and determining their potential public health risk remains a challenge. Direct unprotected exposure to infected poultry (e.g., at live-bird markets or in backyard farms) is the greatest known risk for human infection (10). Although rapid sequencing of these viruses might identify markers for transmissibility to humans, uncertainty regarding the risk to human health might persist until sufficient data for human exposures and outcomes have been collected. International organizations have developed tools to assess such risk: these tools include the FluRisk project

Author affiliations: European Centre for Disease Prevention and Control, Stockholm, Sweden (C. Adlhoch, P. Penttinen); Public Health England, London, UK (G. Dabrera, R. Pebody)

DOI: https://doi.org/10.3201/eid2410.180269 of the European Food Safety Authority (11), the Tool for Influenza Pandemic Risk Assessment of the World Health Organization (12), and the Influenza Risk Assessment Tool of the US Centers for Disease Control and Prevention (13). However, how these risks are managed locally might vary.

For early identification of new influenza viruses potentially transmissible to humans and to prevent and prepare for these threats, avian influenza surveillance is essential. The surveillance and control of avian influenza in poultry and wild birds is laid down in EU legislation $(14,15)$. Legally mandated measures include establishing control and surveillance zones after detection of relevant viruses; these measures are limited to $\mathrm{H} 5$ and $\mathrm{H} 7$ subtypes, although other avian influenza virus subtypes have also infected humans (16). To control an outbreak and prevent further spread, affected poultry flocks must be quickly destroyed, which might expose the involved agricultural workers and animal health staff to avian influenza infection. This necessity poses particular challenges when avian influenza viruses differ in sequence from those already known because there will initially often be limited or no information about the risk for human illness or laboratory-confirmed infection, and exposures tend to be rare. Thus, decision makers might struggle to balance the need to control an avian influenza outbreak against the need to prevent infection among exposed persons.

After circulating in countries in Asia, $\mathrm{H} 5 \mathrm{~N} 8$ virus clade 2.3.4.4 group A was introduced into Europe during the winter of 2014-15 $(17,18)$. Viruses of this clade had been shown to have a low ability to transmit between ferrets, to exhibit low-to-moderate virulence in mammals, and not to be transmissible by airborne infection (19-21). During and after the winter of 2016, a related, but genetically distinct influenza H5N8 virus was detected in Europe; in addition, reassortant influenza $\mathrm{H} 5 \mathrm{~N} 5$ and $\mathrm{H} 5 \mathrm{~N} 6$ viruses emerged. Because the influenza season progressed along the fall migratory routes for wild birds from Siberia across Asia into Europe, large numbers of dead wild birds and outbreaks in poultry flocks were associated with $\mathrm{H} 5 \mathrm{~N} 8$ virus clade 2.3.4.4 group B (22). H5N8 virus had not previously

${ }^{1}$ Members of this group are listed at the end of this article. 
been widely seen in Europe, and the risk for bird-to-human transmission was not clear. Avian outbreaks increased in number, size, and distribution among migratory and resident birds, zoo birds, backyard farms, and poultry holdings, to a scale not previously observed for a subtype during a winter season $(23,24)$. Overall, 24 of the 31 the European Union/European Economic Area (EU/EEA) countries, neighboring countries, Israel, and countries in the Middle East were facing large avian influenza outbreaks in poultry or wild birds during the study period, and there was great uncertainty about the risk for virus transmission from birds to humans (25).

Shortly after the first report of influenza H5N8 virus in Europe, the European Centre for Disease Prevention and Control (ECDC) published a risk assessment and considered the risk to the general public as being low (26). However, this report suggested that exposed persons should wear personal protective equipment (PPE), be followed up after exposure, and be provided with antiviral prophylaxis according to national guidelines (26). A first rapid follow-up assessment in 8 EU countries affected in 2014-15 that continued through December 2016 showed a heterogeneous implementation of control measures (27). As the outbreak continued, many more EU countries were affected, and ECDC received questions regarding optimal control measures.

The aim of this study was to describe local approaches to risk assessment and control measures used in all EU/ EEA countries and Israel and to rapidly evaluate the risk for transmission to humans exposed to infected birds, to prioritize ongoing preparedness activities for future outbreaks of emerging avian influenza viruses. We hope that, as a result, countries would be enabled to harmonize their response activities related to $\mathrm{H} 5 \mathrm{~N} 8$ virus and be better prepared for future outbreaks caused by emerging avian influenza viruses.

\section{Methods}

We developed a structured online questionnaire to collect information on preparedness and response arrangements of each country in relation to $\mathrm{H} 5 \mathrm{~N} 8$ virus. This questionnaire covered public health risk assessments and recommendations regarding use of PPE, antiviral prophylaxis, health surveillance of exposed persons, management of symptomatic exposed persons and use of seasonal influenza vaccination, as well as cross-sector collaboration and communication. The primary design of the questionnaire was revised after discussion with several national operational contact points (OCPs) for influenza. These OCPs are nationally nominated epidemiology and virology specialists in the EU/EEA countries for any interaction with ECDC on operational matters related to influenza. On February 17, 2017, OCPs for influenza from all 31 EU/EEA Member
States were invited by email to participate in this survey. Through a webinar on March 7, 2017, preliminary results were shared with the National Focal Points and OCPs. In addition, Israel contacted ECDC to inquire about protection measures during H5N8 outbreaks in affected EU/EEA countries and was also invited to participate in this study. The online survey was closed on May 31, 2017 (Figure 1).

The total number of countries invited (31 EU/EEA plus Israel) was used to calculate the response rate. We analyzed responses by using simple descriptive statistics with the number of respondents as the denominator, including numbers of countries with risk assessments at the national and individual-outbreak levels, content of national recommendations for exposed persons, provision of antiviral prophylaxis, and use of seasonal influenza vaccination. We also summarized the types of case definitions used for symptomatic possible human cases of avian influenza among exposed persons, as well as the number of persons exposed and tested for possible avian influenza infection.

\section{Results}

Of the 32 countries invited to complete the questionnaire, 23 (72\%) responded: 22 EU/EEA Member States and Israel. Of these 23 countries, 18 reported avian influenza outbreaks; 5 did not report any outbreaks but provided a comprehensive picture of their preparedness and response (Figure 2).

National risk assessments in relation to $\mathrm{H} 5 \mathrm{~N} 8$ virus were conducted in $19(83 \%)$ of 23 countries, and all but 2 assessed the public health risk as low, negligible, or very low. For the remaining 2 countries, 1 reported a medium risk to public health and 1 reported a low risk for the general public but a real risk for poultry workers. The real risk was based on the assumption that single infections in humans after direct contact with sick birds cannot be excluded. In 1 country, the risk assessment was performed together with veterinary experts and also updated over the course of the outbreaks. Twenty-two countries reported that their assessment considered the rapid risk assessment of ECDC. One country referred to its past experience with outbreaks of H5N8 influenza during 2014-15, and 7 referred to the fact that, to date, no infections in humans had been observed worldwide. Thirteen $(59 \%)$ of 22 countries reported that local risk assessments were also undertaken in relation to individual poultry outbreaks or detection of $\mathrm{H} 5 \mathrm{~N} 8$ virus in wild birds.

\section{Recommendations for Protection of Persons Exposed to H5N8 Virus}

Guidelines for the most relevant occupational groups responding to detections of $\mathrm{H} 5 \mathrm{~N} 8$ virus were in place in each participating country; $>85 \%$ of countries had recommendations for farmers (20 countries), cullers (20 countries), and 
veterinarians (22 countries). Seventeen countries (81\%) had recommendations for members of the public directly exposed to infected birds. Six countries had recommendations for specific exposed groups, such as firefighters, police officers, and rescuers; employees involved in culling; fishery inspectors; hunters; taxidermists; bird ringers; ornithologists; and birdwatchers.

Most guidelines for PPE recommended during wild bird outbreaks included use of gloves (21/23 countries), goggles (19/23), masks (19/23), and body suits (18/23). In addition, boots ( 3 countries), disinfection material (1), disposable aprons (1), handwashing (1), disposable hair nets (1), disposable gloves (1), and minimum filtering facepiece 2 (FFP2) masks (1) were recommended.

Recommended PPE to be used during poultry outbreaks included goggles (21/22 countries), gloves (21/22), masks (21/22), and body suits (21/23). Other materials and measures required in some countries were boots/rubber boots (6 countries), FFP3 respirator or mask (2), visor (1), protective gloves (1), disposable aprons (1), and covering of the hair (1).

For all but 4 countries, PPE recommendations were the same for influenza outbreaks in poultry and wild birds. In
Italy, Israel, Norway, and Sweden, recommendations for detection of influenza outbreaks in wild birds were either less stringent than those for outbreaks in poultry or not documented at the national level. For example, in Norway, differences were related to the type of mask (minimum FFP2 for outbreaks in wild birds, protection level 3 for outbreaks in poultry) and type of gloves (disposable gloves for outbreaks in wild birds and thicker protection gloves for outbreaks in poultry).

\section{Identification and Follow-Up of Exposed Persons}

In 10 countries, exposed persons were identified through the local veterinary authority alone or jointly by public health authorities together with local veterinary authorities, food safety authorities, or in liaison with the Department of Agriculture and the Marine. Other ways of identification included epidemiologic investigations or self-monitoring and reporting by the local practitioner to the regional public health authority.

Thirteen countries reported definitions of different levels of exposure that varied in their level of detail (Table 1, https://wwwnc.cdc.gov/EID/article/24/10/18-0269-T1). Major categories included type of protection (protected,

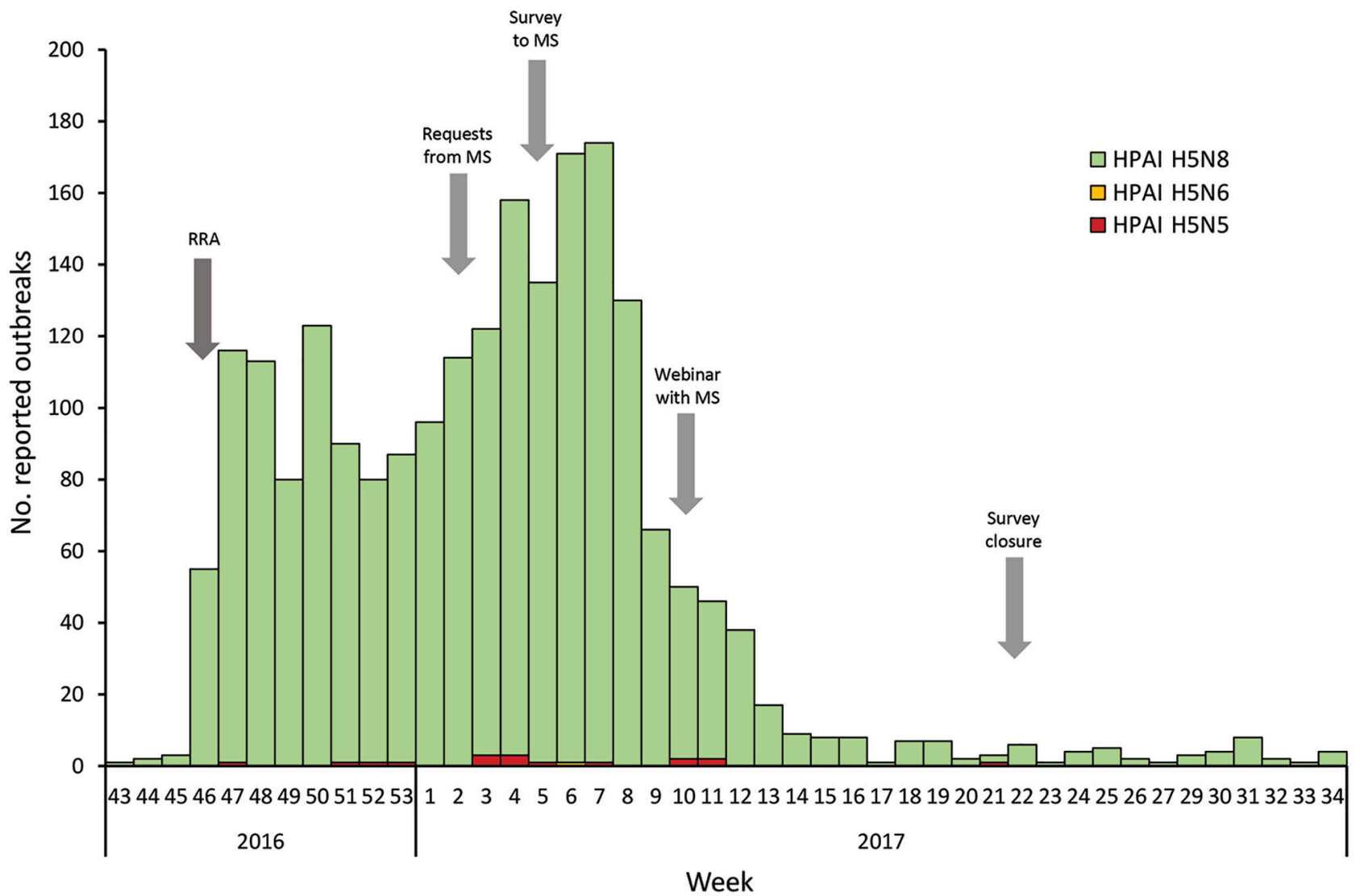

Figure 1. Number of reported highly pathogenic avian influenza outbreaks in birds and timeline of the European Centre for Disease Prevention and Control survey (arrows), by week, European Union/European Economic Area and Israel, 2016-17. HPAI, highly pathogenic avian influenza; MS, Member State; RRA, rapid risk assessment. 
Avian influenza $\mathrm{A}(\mathrm{H} 5 \mathrm{Nx})$ outbreaks and participation in the survey

Outbreaks and participation

No outbreaks, but participation

Outbreaks, no participation

No outbreaks, no participation
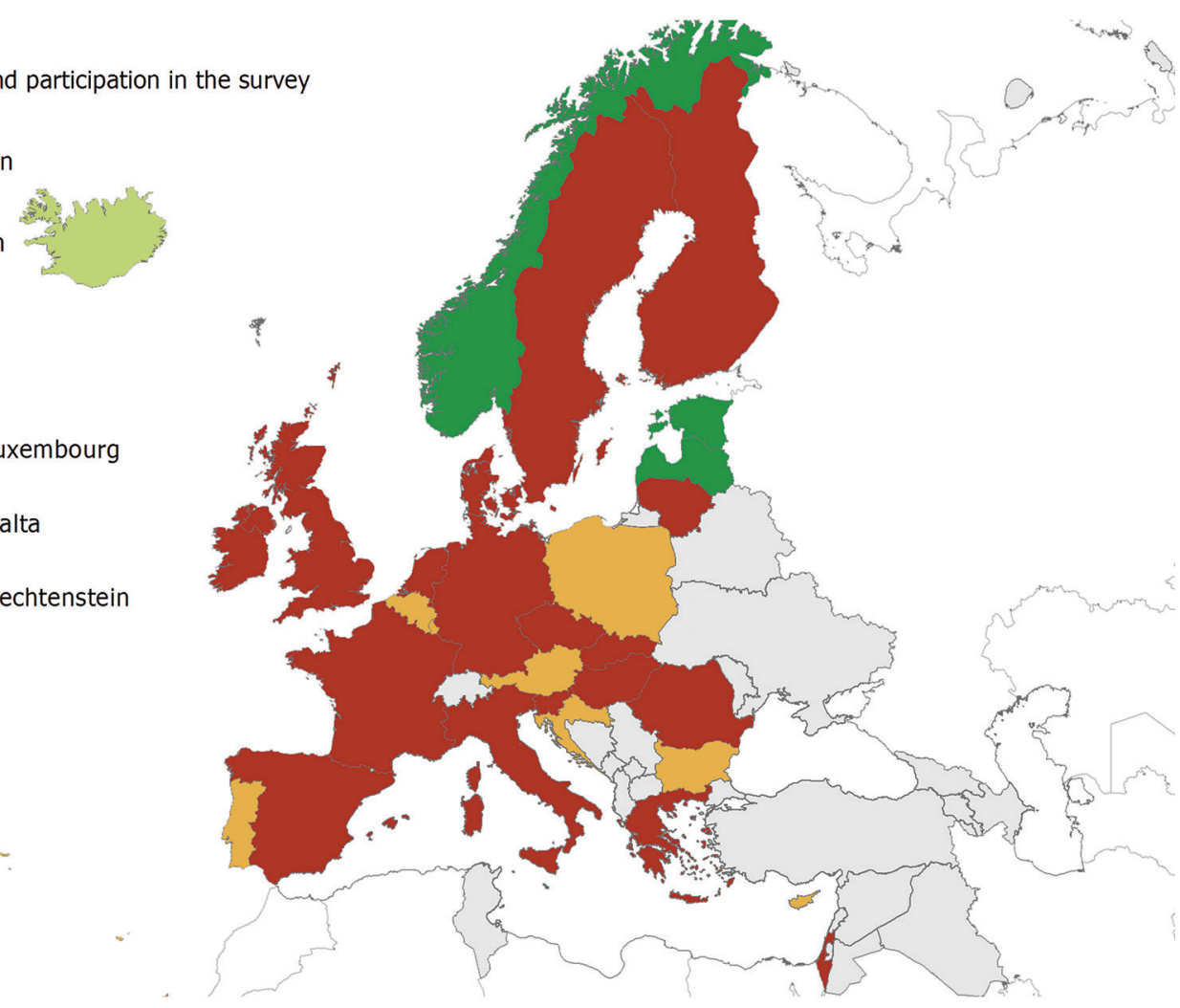

Figure 2. Reported highly pathogenic avian influenza outbreaks and participation in the European Centre for Disease Prevention and Control survey, by country, European Union/European Economic Area and Israel, 2016-17.

unprotected, not wearing appropriate PPE, PPE breach); type of contact (indirect, direct $[\leq 1 \mathrm{~m}]$, skin contact, aerosol); duration of contact (accidentally short, sporadic, over longer period); type of contamination (environment, bird/ dropping, birds in backyard holding area, poultry on farm); context of exposure (occupational, nonoccupational); type of setting for the outbreak (wild bird, backyard, poultry farm); type of activity (wild bird ringing, swabbing, culling, disposal, clean-up); and confirmation status of avian influenza virus (suspected, confirmed, status unclear, status cannot be confirmed).

All but 1 of the participating countries undertook surveillance of exposed persons according to national guidelines. Ten countries reported active follow-up (i.e., exposed persons were proactively contacted to check on their health status). Thirteen countries reported passive follow-up (i.e., exposed persons were given health advice and instructions on what to do when symptomatic). In 1 country, the decision on whom to follow up and in which way was taken at the local level. Five countries considered active monitoring for all persons in close and direct contact with infected birds, and 5 other countries considered active surveillance only for persons who were unprotected when exposed. In the remaining countries, no active monitoring was under- taken. One country replied that because of a heavy workload, active surveillance activities had to be stopped. One country had to follow up persons across national borders within the EU.

Eighteen countries used case definitions for acute respiratory infection or influenza-like illness (i.e., fever with any symptoms of acute respiratory infection) in association with exposure to an infected flock/bird as a case definition to identify a possible human case of avian influenza: 10 countries used both syndromes, and 4 countries used either acute respiratory infection or influenza-like illness. Six countries used conjunctivitis, 1 country included severe acute respiratory infection, and another country used gastrointestinal symptoms in association with exposure.

Six countries reported to have actively followed up 254 exposed persons, and 4 countries reported to have passively followed up 274 persons. Five countries did not have this information at the national level, and 7 countries reported that none of any exposed persons had been monitored. Six countries reported that they had tested 29 persons for $\mathrm{H} 5 \mathrm{~N} 8$ virus; all test results were negative, but 1 person was positive for seasonal $\mathrm{H} 3 \mathrm{~N} 2$ virus.

The Netherlands and the United Kingdom reported planning to evaluate the transmission risk for exposed 
persons. The Netherlands reported conducting a serosurvey to follow up exposed persons and identify any possible transmission events.

\section{Antiviral Prophylaxis and Vaccination}

Eight countries reported that antiviral prophylaxis was either not relevant for $\mathrm{H} 5 \mathrm{~N} 8$ or not recommended. The remaining countries reported that use of antiviral drugs for exposed persons differed depending on level of protection and exposure according to specific recommendations. During outbreaks, antiviral drugs were more commonly provided when exposed persons had not been wearing appropriate PPE or a breach of PPE had been reported (Table 2). Other exposed persons without PPE who would be offered postexposure prophylaxis included family members of poultry farmers, members of the public handling sick or dead birds or their fecal matter, contact persons of confirmed case-patients infected with avian influenza, and occupationally exposed persons wearing PPE but in whom influenza-like symptoms developed.

Most (15/22, 68\%) countries reported a recommendation for seasonal influenza vaccination of poultry workers in general and a similar $(13 / 21,62 \%)$ number reported to have actually recommended vaccination during these outbreaks. During the webinar, participants explained that the period between vaccination and involvement in culling operations was assessed as being too short for sufficient protection at the individual level.

\section{Cross-Collaboration and Communication}

Most (16/21, 76\%) respondents reported that animal and public health laboratories cooperated by sharing specimens. Two thirds of respondents also reported that information had been shared with primary care providers $(14 / 21,67 \%)$ and local hospitals $(14 / 20,70 \%)$ to increase awareness of local avian influenza outbreaks.

\section{Discussion}

During the winter of 2016-17, Europe faced the longest period of avian influenza outbreaks ever recorded. These outbreaks required $\approx 25$ million poultry to be destroyed or culled as part of preventive action (30). According to the
EU reference laboratory for avian influenza, as October 4, 2017, EU Member States had reported 2,781 outbreaks of H5N8 influenza in poultry, wild birds, and captive birds, as well as 20 outbreaks of H5N5 influenza and 1 outbreak of H5N6 influenza in a wild bird (31). In our study, 18 of the 25 avian influenza-affected countries provided feedback, and 5 countries not affected also participated.

After initial identification of a new avian influenza reassortant virus, there was uncertainty about transmissibility of the virus to humans. The large number of culled birds provides numerous possible exposure events for humans and also provides useful opportunities to understand potential transmissibility of this virus from birds to humans. No laboratory-confirmed cases among symptomatic persons have been identified, although a large number of workers were involved.

Despite large numbers of workers exposed to infected birds across the affected countries, of the 195 exposed workers who were identified exhibiting symptoms of influenza-like illness or acute respiratory infection and were laboratory tested, all showed negative results. This finding could be caused by strict prevention and control measures applied in combination with an assumed poor ability of the virus to be transmitted to humans (as with other avian influenza viruses) or a combination of both factors. However, not all persons involved during outbreaks and exposed to infected birds were identified and followed up, resulting in a still high level of uncertainty. Also, asymptomatic transmission would not have been detected. Follow-up activities are resource intensive, and 1 country, for example, had to stop active follow-up of exposed persons because of limited capacity, and more risk-based passive approaches had to be implemented. Such an adapted risk-based approach for the management of exposed persons could help prioritize use of sparse resources in the most efficient way and would be especially useful if avian influenza viruses that are more transmissible from birds to humans were introduced into Europe or were to emerge.

Recommendations for the use of antiviral prophylaxis also differed among the countries. The number of countries recommending antiviral drugs increased from $30 \%$ to $50 \%$ when unprotected exposure to an infected

Table 2. Recommendation for antivirus prophylaxis for different exposed groups, European Union/European Economic Area and Israel, 2016-17*

\begin{tabular}{|c|c|c|c|c|}
\hline \multirow[b]{2}{*}{ Antivirus treatment } & \multicolumn{4}{|c|}{ No. countries with recommendations } \\
\hline & $\begin{array}{c}\text { Occupationally } \\
\text { exposed persons } \\
\text { wearing PPE, } n=21\end{array}$ & $\begin{array}{l}\text { Occupationally exposed } \\
\text { persons not wearing PPE } \\
\text { or PPE breach, } n=22\end{array}$ & $\begin{array}{c}\text { Occupational } \\
\text { groups handling sick } \\
\text { or dead poultry and } \\
\text { birds, } n=21\end{array}$ & $\begin{array}{l}\text { Other } \\
\text { exposed } \\
\text { persons, } \\
\mathrm{n}=21\end{array}$ \\
\hline No prophylaxis & 14 & 11 & 13 & 12 \\
\hline Preexposure prophylaxis & 2 & 2 & 2 & 1 \\
\hline Preexposure and postexposure prophylaxis & 1 & 1 & 1 & 1 \\
\hline Postexposure prophylaxis & 3 & 8 & 2 & 4 \\
\hline Unknown or no answer & 1 & 0 & 3 & 3 \\
\hline
\end{tabular}

${ }^{*} \mathrm{PPE}$, personal protective equipment. 
bird was observed. However, it is unknown how well the recommendations were followed onsite. It is similarly not possible to comment on the extent to which antiviral prophylaxis for exposed persons contributed to the observed absence of acute infections with $\mathrm{H} 5 \mathrm{~N} 8$ virus despite following up $>500$ persons. As commented previously, asymptomatic infections could have occurred and would not have been identified by the follow-up processes described in this study.

During these outbreaks, many countries had to rely on different authorities for follow-up of exposed persons. Different responsibilities between these authorities and local, regional, and national levels hampered comprehensive information about numbers of persons exposed. Only 9 countries were able to provide at least some veterinary data, which suggested that $\approx 1,570$ persons were exposed during 258 outbreaks (30). The total number of exposed persons or exposure events during outbreaks in all affected countries remains unknown. If an avian influenza virus with the capacity to be transmitted to humans enters Europe or emerges, it will be necessary to have comprehensive systems able to better identify and follow up exposed persons, test suspected cases, recognize severe disease, and prevent spread to the community.

Most avian influenza outbreaks occurred during the same time as seasonal influenza outbreaks when $\mathrm{H} 3 \mathrm{~N} 2$ viruses were dominant across Europe and caused high disease burden and excess mortality rates in many EU/EEA countries (32). Detection of seasonal influenza viruses in persons also exposed to avian influenza viruses highlights the possibility and risk for reassortment events. Therefore, vaccination with seasonal influenza vaccine for occupationally exposed persons needs to be carefully reassessed whenever facing avian influenza outbreaks. Considerations should include whether these outbreaks coincide with circulation of seasonal influenza viruses and whether seasonal influenza vaccine is available in sufficient quantities.

The avian influenza outbreaks described in this report show examples of successful cooperation between veterinary and public health services in some countries in sharing specimens and collaboration to identify exposed persons. However, challenges remain and efforts toward a One Health approach should be continued. Serosurveys in epidemiologic studies to follow up exposed cohorts and identify possible transmission events might better describe the risk for transmission and help reduce uncertainty when assessing the risk for those newly emerging viruses, despite known limitations regarding subtype specificity of serologic testing $(33,34)$. Despite a wide diversity in the recommendations for use of PPE and of antiviral prophylaxis for exposed persons, we found no evidence of birdto-human transmission of infection. The reasons for this finding might be related to the need for a minimum level of PPE and use of antiviral drugs, although another useful potential factor is likely to be the poor ability of the virus to be transmitted to humans. Finally, a thorough review of the measures recommended during these outbreaks in view of the results of our survey might help to identify critical points and challenges in each country that can be addressed and resolved to be better prepared for future outbreaks (35).

In conclusion, this study enabled us to put preparedness and control activities during an avian influenza emergency into a realistic context. The information gathered provided a clearer understanding of measures taken also as examples for countries not affected at the time of the survey.

Members of Country Experts: Jan Kyncl and Martina Havlickova (National Institute of Public Health, Prague, Czech Republic); Tyra Grove Krause (Statens Serum Institut, Copenhagen, Denmark); Irina Dontsenko (Health Board Estonia, Tallinn, Estonia); Niina Ikonen and Outi Lyytikäinen (National Institute for Health and Welfare, Helsinki, Finland); Isabelle Bonmarin (Sante Publique France, Paris, France); Silke Buda (Robert Koch Institute, Berlin, Germany); Vasileia Konte and Kostas Mitrou (Hellenic Centre for Disease Control and Prevention, Athens, Greece); Katalin Kristalovics (National Center for Epidemiology, Budapest, Hungary); Joan O’Donnell (Health Service Executive-Health Protection Surveillance Centre, Dublin, Ireland); Shepherd Roee Singer (Ministry of Health Division of Epidemiology, Jerusalem, Israel); Caterina Rizzo, Maria Rita Castrucci, and Luca Busani (Istituto Superiore di Sanità, Rome, Italy); Raina Nikiforova (Centre for Disease Prevention and Control of Latvia, Riga, Latvia); Marina Jamnicki Abegg (Office of Public Health, Liechtenstein); Rasa Liausediene (Centre for Communicable Diseases and AIDS, Vilnius, Lithuania); Tanya Melillo (Health Regulation, Malta); André Jacobi, Adam Meijer, and Marit de Lange (National Institute for Public Health and the Environment, Bilthoven, the Netherlands); Ragnhild Tønnessen, Nina Sorknes (Norwegian Institute of Public Health, Oslo, Norway); Odette Popovici and Rodica Popescu (National Institute of Public Health, Romania, National Centre for Communicable Diseases Surveillance and Control, Bucharest, Romania); Adriana Mečochová (Public Health Authority of the Slovak Republic, Bratislava, Slovakia); Maja Socan and Katarina Prosenc (National Institute of Public Health and National Laboratory for Health, Environment and Food, Ljubljana, Slovenia); María José Sierra Moros (Ministry of Health, Social Services and Equity, Madrid, Spain); and Anders Wallensten (Folkhälsomyndigheten, Stockholm, Sweden).

\section{Acknowledgments}

We thank Phillip Zucs and Piotr Kramarz for their reviews and helpful comments and all persons involved in the study during recent avian influenza outbreaks.

The study was supported by the ECDC. 


\section{About the Author}

Dr. Adlhoch is a veterinarian, infectious diseases specialist, and epidemiologist at the European Centre for Disease Prevention and Control, Stockholm, Sweden. Her research interests focus on zoonoses.

\section{References}

1. Kang Y, Liu L, Feng M, Yuan R, Huang C, Tan Y, et al. Highly pathogenic H5N6 influenza A viruses recovered from wild birds in Guangdong, southern China, 2014-2015. Sci Rep. 2017;7:44410. http://dx.doi.org/10.1038/srep44410

2. Su S, Gu M, Liu D, Cui J, Gao GF, Zhou J, et al. Epidemiology, evolution, and pathogenesis of H7N9 influenza viruses in five epidemic waves since 2013 in China. Trends Microbiol. 2017;25:713-28. http://dx.doi.org/10.1016/j.tim.2017.06.008

3. To KK, Tsang AK, Chan JF, Cheng VC, Chen H, Yuen KY. Emergence in China of human disease due to avian influenza A(H10N8) — cause for concern? J Infect. 2014;68:205-15. http://dx.doi.org/10.1016/j.jinf.2013.12.014

4. Wei SH, Yang JR, Wu HS, Chang MC, Lin JS, Lin CY, et al. Human infection with avian influenza A H6N1 virus: an epidemiological analysis. Lancet Respir Med. 2013;1:771-8. http://dx.doi.org/10.1016/S2213-2600(13)70221-2

5. Uyeki TM. Global epidemiology of human infections with highly pathogenic avian influenza A (H5N1) viruses. Respirology. 2008;13(Suppl 1):S2-9. http://dx.doi.org/10.1111/j.1440-1843. 2008.01246.x

6. Jiang H, Wu P, Uyeki TM, He J, Deng Z, Xu W, et al. Preliminary epidemiologic assessment of human infections with highly pathogenic avian influenza A(H5N6) virus, China. Clin Infect Dis. 2017;65:383-8. http://dx.doi.org/10.1093/cid/cix334

7. European Commission. Decision no. 1082/201313/EU of the European Parliament and of the Council of 22 October 2013 on serious cross-border threats to health and repealing Decision no. 2119/98/EC; 2013 [cited 2013 Feb 21]. http://eur-lex.europa.eu/ LexUriServ/LexUriServ.do?uri=OJ:L:2013:293:0001:0015:EN:PDF

8. European Commission. 2008/426/EC: Commission Decision of 28 April 2008 amending Decision 2002/253/EC laying down case definitions for reporting communicable diseases to the Community network under Decision No 2119/98/EC of the European Parliament and of the Council (notified under document no. C(2008 1589) (text with EEA relevance); 2008 [cited 2014 Feb 21]. https://eur-lex.europa.eu/legal-content/EN/TXT/?qid=15312365037 77\&uri=CELEX:32008D0426

9. World Health Organization. International health regulations (2005), 3rd ed. 2016 [cited 2017 Mar 6]. http://www.who.int/ihr/ publications/9789241580496/en/

10. Yuan J, Lau EH, Li K, Leung YH, Yang Z, Xie C, et al. Effect of live poultry market closure on avian influenza A(H7N9) virus activity in Guangzhou, China, 2014. Emerg Infect Dis. 2015;21:1784-93. http://dx.doi.org/10.3201/eid2110.150623

11. Munoz O, De Nardi M, van der Meulen K, van Reeth K, Koopmans M, Harris K, et al. Genetic adaptation of influenza A viruses in domestic animals and their potential role in interspecies transmission: a literature review. EcoHealth. 2015.

12. World Health Organization. Tool for influenza pandemic risk assessment (TIPRA), 2016 [cited 2017 Sep 21]. http://www.who. int/influenza/areas_of_work/human_animal_interface/tipra/en/

13. Cox NJ, Trock SC, Burke SA. Pandemic preparedness and the influenza risk assessment tool (IRAT). Curr Top Microbiol Immunol. 2014;385:119-36. http://dx.doi.org/10.1007/82_2014_419

14. European Commission. Commission decision 2010/367/EU on the implementation by member states of surveillance programmes for avian influenza in poultry and wild birds, 2015 [cited 2015 Mar
11]. http://eur-lex.europa.eu/legal-content/EN/TXT/?qid=14260626 27792\&uri $=$ CELEX:32010D0367

15. European Commission. Council directive 2005/94/EC of 20 December 2005 on community measures for the control of avian influenza and repealing directive 92/40/EEC [cited 2014 Nov 10]. http://eur-lex.europa.eu/legal-content/EN/TXT/?qid=14156092287 14\&uri=CELEX:32005L0094

16. Freidl GS, Meijer A, de Bruin E, de Nardi M, Munoz O, Capua I, et al.; FLURISK Consortium. Influenza at the animal-human interface: a review of the literature for virological evidence of human infection with swine or avian influenza viruses other than A(H5N1). Euro Surveill. 2014;19:20793. http://dx.doi.org/ 10.2807/1560-7917.ES2014.19.18.20793

17. Núñez A, Brookes SM, Reid SM, Garcia-Rueda C, Hicks DJ, Seekings JM, et al. Highly pathogenic avian influenza H5N8 clade 2.3.4.4 virus: equivocal pathogenicity and implications for surveillance following natural infection in breeder ducks in the United Kingdom. Transbound Emerg Dis. 2016;63:5-9. http://dx.doi.org/10.1111/tbed.12442

18. Bouwstra RJ, Koch G, Heutink R, Harders F, van der Spek A, Elbers AR, et al. Phylogenetic analysis of highly pathogenic avian influenza $\mathrm{A}(\mathrm{H} 5 \mathrm{~N} 8)$ virus outbreak strains provides evidence for four separate introductions and one between-poultry farm transmission in the Netherlands, November 2014. Euro Surveill. 2015;20:21174. http://dx.doi.org/10.2807/1560-7917.ES2015.20.26.21174

19. Pulit-Penaloza JA, Sun X, Creager HM, Zeng H, Belser JA, Maines TR, et al. Pathogenesis and transmission of novel highly pathogenic avian influenza $\mathrm{H} 5 \mathrm{~N} 2$ and $\mathrm{H} 5 \mathrm{~N} 8$ viruses in ferrets and mice. J Virol. 2015;89:10286-93. http://dx.doi.org/10.1128/ JVI.01438-15

20. Richard M, Herfst S, van den Brand JM, Lexmond P, Bestebroer TM, Rimmelzwaan GF, et al. Low virulence and lack of airborne transmission of the Dutch highly pathogenic avian influenza virus H5N8 in ferrets. PLoS One. 2015;10:e0129827. http://dx.doi.org/10.1371/journal.pone.0129827

21. Kim YI, Pascua PN, Kwon HI, Lim GJ, Kim EH, Yoon SW, et al. Pathobiological features of a novel, highly pathogenic avian influenza A(H5N8) virus. Emerg Microbes Infect. 2014;3:e75. http://dx.doi.org/10.1038/emi.2014.75

22. European Food Safety Authority. European Centre for Disease Control. European Union Reference Laboratory for Avian Influenza. Brown I, Mulatti P, Smietanka K, Staubach C, Willeberg P, Adlhoch C, et al. Avian influenza overview October 2016-August 2017. European Food Safety Authority Journal. 2017; 15:e05018-n/a [cited 2018 May 8]. https://efsa.onlinelibrary.wiley. com/doi/full/10.2903/j.efsa.2017.5018

23. Pohlmann A, Starick E, Grund C, Höper D, Strebelow G, Globig A, et al. Swarm incursions of reassortants of highly pathogenic avian influenza virus strains H5N8 and H5N5, clade 2.3.4.4b, Germany, winter 2016/17. Sci Rep. 2018;8:15. http://dx.doi.org/10.1038/ s41598-017-16936-8

24. Beerens N, Heutink R, Bergervoet SA, Harders F, Bossers A, Koch G. Multiple reassorted viruses as cause of highly pathogenic avian influenza A(H5N8) virus epidemic, the Netherlands, 2016. Emerg Infect Dis. 2017;23:1974-81. http://dx.doi.org/10.3201/eid2312.171062

25. World Organisation for Animal Health. Avian influenza portal [cited 2014 Nov 25]. http://www.oie.int/en/animal-health-in-theworld/avian-influenza-portal/what-is-avian-influenza/h5n1notified-2003-2009/

26. European Centre for Disease Prevention and Control. Outbreaks of highly pathogenic avian influenza A(H5N8) in Europe. Updated 18 November 18, 2016; 2016 [cited 2017 Sep 6]. https://ecdc.europa. eu/sites/portal/files/media/en/publications/Publications/riskassessment-avian-influenza-H5N8-europe.pdf

27. Adlhoch C, Brown IH, Angelova SG, Bálint Á, Bouwstra R, Buda S, et al. Highly pathogenic avian influenza A(H5N8) 
outbreaks: protection and management of exposed people in Europe, 2014/15 and 2016. Euro Surveill. 2016;21:30419. http://dx.doi.org/10.2807/1560-7917.ES.2016.21.49.30419

28. Robert Koch Institute. Recommendations of the Robert Koch Institute for the prevention of persons with an increased risk of exposure to (highly pathogenic) avian influenza A/H5, 2006 [in German] [cited 2018 May 8]. https://www.rki.de/DE/

Content/InfAZ/Z/ZoonotischeInfluenza/Empfehlungen 1.pdf?_blob=publicationFile

29. Robert Koch Institute. Monitoring of exposed individuals in outbreaks of avian influenza in birds/poultry, 2007 [cited 2017 Sep 19]. https://www.rki.de/DE/Content/InfAZ/Z/ZoonotischeInfluenza/Monitoring_exponierter_Personen_bei_Ausbruch_von aviaerer_Influenza.html? $\mathrm{nn}=\mathbf{2 3 8 2 0 7 8}$

30. Brown I, Mulatti P, Smietanka K, Staubach C, Willeberg P, Adlhoch C, et al. Avian influenza overview October 2016-August 2017, 2017 [cited 2017 Oct 16]. https://ecdc.europa.eu/en/ publications-data/ecdcefsa-joint-report-avian-influenza-overviewoctober-2016-august-2017

31. Animal and Plant Health Agency. Situation assessment following detection and spread of H5 HPAI in EU member states since October 2016, 2017 [cited 2017 Oct 18]. https://science.vla.gov.uk/ flu-lab-net/docs/ai-outbreak-situation-report041017.pdf
32. Vestergaard LS, Nielsen J, Krause TG, Espenhain L, Tersago K, Bustos Sierra N, et al. Excess all-cause and influenza-attributable mortality in Europe, December 2016 to February 2017. Euro Surveill. 2017;22:30506. http://dx.doi.org/10.2807/1560-7917. ES.2017.22.14.30506

33. de Bruin E, Zhang X, Ke C, Sikkema R, Koopmans M. Serological evidence for exposure to avian influenza viruses within poultry workers in southern China. Zoonoses Public Health. 2017;64:e519. http://dx.doi.org/10.1111/zph.12346

34. Sikkema RS, Freidl GS, de Bruin E, Koopmans M. Weighing serological evidence of human exposure to animal influenza viruses: a literature review. Euro Surveill. 2016;21:30388. http://dx.doi.org/10.2807/1560-7917.ES.2016.21.44.30388

35. Harris KA, Freidl GS, Munoz OS, von Dobschuetz S, De Nardi M, Wieland B, et al.; FLURISK Consortium. Epidemiological risk factors for animal influenza A viruses overcoming species barriers. EcoHealth. 2017;14:342-60. http://dx.doi.org/10.1007/s10393-017-1244-y

Address for correspondence: Cornelia Adlhoch, European Centre for Disease Prevention and Control, Gustav III:s Blvd 40, 16973 Solna, Sweden; email: cornelia.adlhoch@ecdc.europa.eu

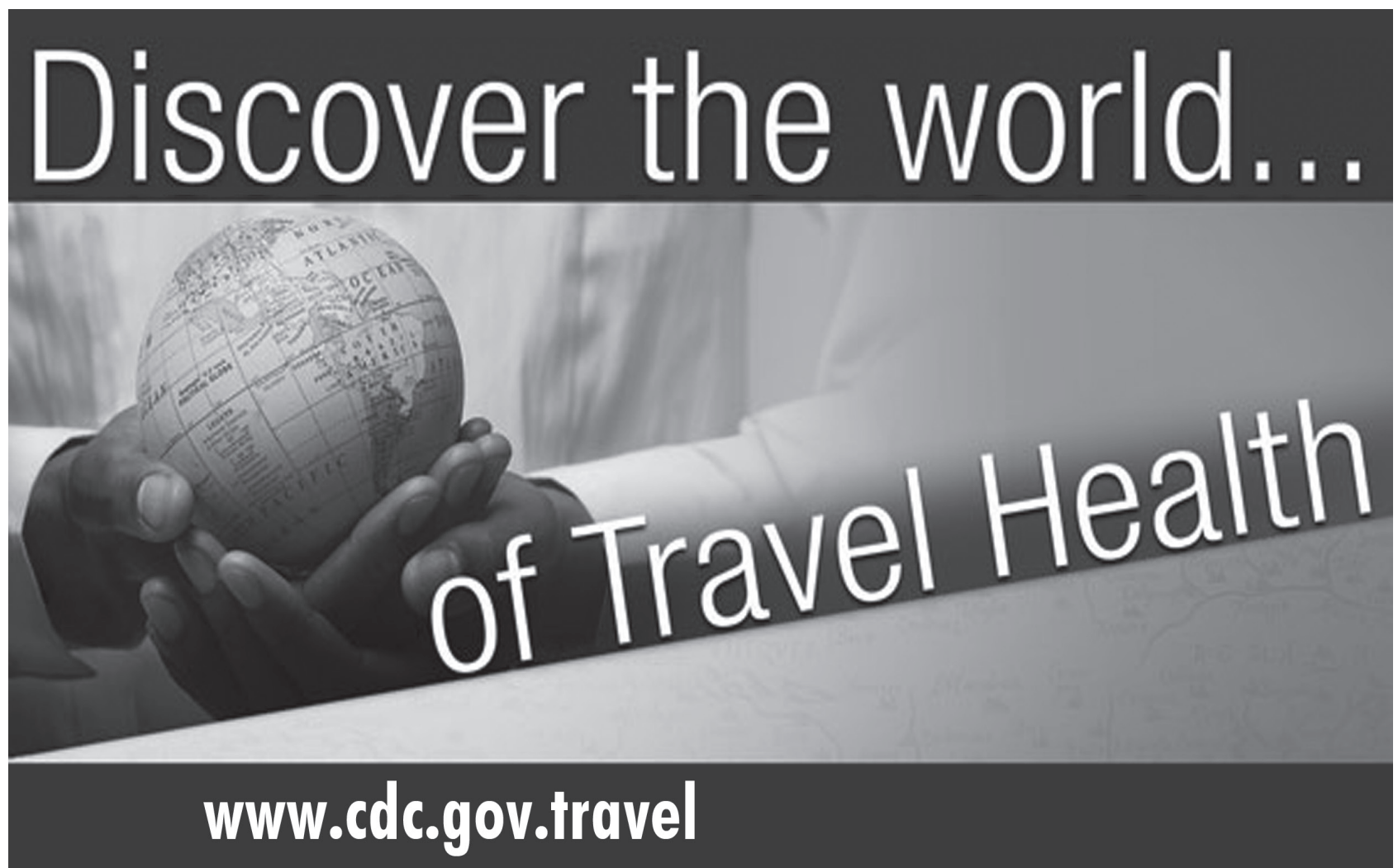

Visit the CDC Travelers' Health website for up-to-date information on global disease activity and international travel health recommendations.

\section{Department of Health and Human Services \\ Centers for Disease Control and Prevention}

